\title{
OPEN Direct and Indirect endocrine-mediated suppression of human endometrial CD8+T cell cytotoxicity
}

\author{
Z. Shen ${ }^{1}$, M. Rodriguez-Garcia ${ }^{2}$, M. V. Patel ${ }^{1} \&$ C. R. Wira ${ }^{1 凶}$
}

Regulation of endometrial (EM) CD8+T cells is essential for successful reproduction and protection against pathogens. Suppression of CD8+T cells is necessary for a tolerogenic environment that promotes implantation and pregnancy. However, the mechanisms regulating this process remain unclear. Sex hormones are known to control immune responses directly on immune cells and indirectly through the tissue environment. When the actions of estradiol $\left(E_{2}\right)$, progesterone $(P)$ and TGF $\beta$ on EM CD8+T cells were evaluated, cytotoxic activity, perforin and granzymes were directly suppressed by $E_{2}$ and TGF $\beta$ but not $P$. Moreover, incubation of polarized EM epithelial cells with $P$, but not $E_{2}$ increased TGF $\beta$ secretion. These findings suggest that $E_{2}$ acts directly on CD8+T cell to suppress cytotoxic activity while $P$ acts indirectly through induction of TGF $\beta$ production. Understanding the mechanisms involved in regulating endometrial CD8+T cells is essential for optimizing reproductive success and developing protective strategies against genital infections and gynecological cancers.

The mucosal immune system in the human female reproductive tract (FRT) is precisely regulated to optimize conditions for successful fertilization, implantation, and pregnancy while providing protection against sexually transmitted infections (STIs) ${ }^{1}$. Unlike other sites in the FRT, the endometrium must protect itself from sexually transmitted pathogens while allowing for the presence of allogeneic spermatozoa and supporting an immunologically distinct fetus. Key to this unique balance within the FRT are the sex hormones, estradiol $\left(\mathrm{E}_{2}\right)$ and progesterone $(\mathrm{P})$, which are secreted by the ovary and whose levels fluctuate during the menstrual cycle and thereby regulate multiple aspects of innate and adaptive immunity ${ }^{2-5}$. During the proliferative phase, $\mathrm{E}_{2}$ is present at low concentrations. However, $\mathrm{E}_{2}$ levels surge at ovulation, decline rapidly, before increasing again during secretory phase, when fertilization and implantation occur. In contrast, $\mathrm{P}$ levels remain low throughout the proliferative and ovulatory phases, before rising and peaking in mid-secretory phase. $\mathrm{E}_{2}$ and $\mathrm{P}$ act directly on FRT immune cells, epithelial cells and fibroblasts to regulate their function, and modulate the production of cytokines, chemokines and growth factors, which in turn regulate the innate and adaptive immune systems. These direct and indirect effects of sex hormones are essential for successful reproduction, and influence susceptibility to STIs in ways that are site-specific in the upper (endometrium, endocervix) and lower (ectocervix, vagina) FRT.

$\mathrm{T}$ cells are central to adaptive immune protection in the FRT and represent a major constituent of leukocytes $(30-60 \%)$ in the endometrium ${ }^{6-9}$. To measure the cytotoxic potential of CD8+T cells, White et al. evaluated the ability of FRT mixed cell suspensions to kill targets using a redirected lysis assay ${ }^{10}$. In addition to demonstrating cytotoxic activity throughout the FRT, these studies demonstrated that endometrial CD3+CD8+T cell cytotoxic activity is markedly influenced by the stage of the menstrual cycle. Cytotoxic activity was elevated during the proliferative phase of the cycle and suppressed during the secretory phase. Interestingly, cytotoxic activity in the endometrium from postmenopausal women was significantly higher than activity at any point of the cycle in premenopausal women. Cycle dependent suppression occurred without changes in total CD8+T cell numbers. More recently, using a time-lapse imaging system to measure direct killing by purified CD8+T cells from the endometrium, we confirmed changes in cytotoxic activity during the menstrual cycle and increased activity following menopause ${ }^{11}$. Maximal suppression of CD8+T cell cytotoxic activity in the endometrium coincided with the time when fertilization and implantation is likely to occur, and therefore may represent a mechanism to avoid recognition and rejection of sperm and fetal cells by maternal endometrial CD8+T cells ${ }^{1}$. Unresolved

${ }^{1}$ Department of Microbiology and Immunology, Geisel School of Medicine at Dartmouth, One Medical Center Drive, Lebanon, NH 03756, USA. ²Department of Immunology, Tufts University School of Medicine, Boston, MA, USA. ${ }^{\boxplus}$ email: charles.r.wira@dartmouth.edu 
however, is the extent to which hormonal changes during the menstrual cycle, act directly or indirectly to regulate $\mathrm{CD} 8+\mathrm{T}$ cells cytotoxic activity in the endometrium.

It is well known that sex hormones, which act both locally and systemically, have a spectrum of immunological effects on adaptive immunity and CD8+T cells in particular. $\mathrm{E}_{2}$ is known to affect the maturation, differentiation, and function of T cells. Others have shown that CD8+T cells express ER $\alpha$ and ER $\beta$ receptors. For example, in rodents, $\mathrm{E}_{2}$ signaling through $\mathrm{ER} \alpha$ was shown to be necessary for full differentiation of CD8+T cells ${ }^{12,13}$. In the human, retrovirally transduced peripheral blood mononuclear cells (PBMC) containing CD8+T cells incubated with $\mathrm{E}_{2}$ reportedly increased their expression of granzyme B, and IFN- $\gamma^{14}$. In contrast, using human CD8+T cells, $\mathrm{P}$ has been shown to reduce IFN- $\gamma$ production upon stimulation ex vivo, although the underlying mechanisms remain to be determined ${ }^{15}$. Beyond reduced production, other studies suggest that $\mathrm{P}$ impairs immune protective functions of antigen-non-specific CD8 T memory cells by inducing IFN- $\gamma$ gene hyper-methylation ${ }^{16}$.

Beyond the direct effects of sex hormones, other soluble mediators are capable of modulating CD8+T cell cytotoxicity. For example, TGF $\beta$ inhibits intestinal CD8+T cell cytotoxicity through the suppression of perforin, without changes in $\mathrm{T}$-bet, Eomes or granzyme $\mathrm{B}^{17}$. We recently reported that endometrial CD8+T cell cytotoxic function is also susceptible to suppression by TGF $\beta$ in both pre- and post-menopausal women, but that the inhibitory effect of TGF $\beta$ is reduced after menopause ${ }^{11}$. In animal studies, we found that TGF $\beta$ is produced by epithelial cells and fibroblasts from the FRT and under hormonal control in that $\mathrm{E}_{2}$ treatment increases the basolateral secretion of biologically active TGF $\beta$ in the rodent ${ }^{18,19}$. However, the mechanisms by which TGF $\beta$ regulates $\mathrm{CD} 8+\mathrm{T}$ cell function in the endometrium remains to be elucidated.

The effects of sex hormones and TGF $\beta$ on cytotoxic activity by CD8+T cells in the human have important implications for women's health, especially as related to successful pregnancy, immunological infertility and protection against sexually transmitted diseases. The objective of this study was to evaluate the roles of $\mathrm{E}_{2}, \mathrm{P}$ and TGF $\beta$ in regulating endometrial CD8+T cell cytotoxic capacity. Our results demonstrate that $\mathrm{E}_{2}$ and TGF $\beta$ act directly on endometrial (EM) CD8+T cells to significantly suppress cytotoxic activity and intracellular perforin and granzyme A levels. In contrast, $\mathrm{P}$ has no direct effect on CD $8+\mathrm{T}$ cells but stimulates TGF $\beta$ secretion by EM epithelial cells. These studies provide insight into mechanisms that control cytotoxic activity in the endometrium to increase reproductive potential.

\section{Results}

Estradiol and TGF $\beta$ suppress cytotoxic activity in CD8+T cells from the endometrium. We have previously demonstrated that cytotoxic activity of EM CD8+T cells is suppressed during the secretory phase of the menstrual cycle and enhanced after menopause ${ }^{10,11}$. In the present study, we investigated whether sex hormones are directly involved in the suppression of CD8+T cell cytotoxic activity. T cells were pretreated for $48 \mathrm{~h}$ with $\mathrm{E}_{2}$ or $\mathrm{P}$ at concentrations known to have physiological effects in vivo ${ }^{20}$ or with TGF $\beta$ for $2 \mathrm{~h}$ prior to measuring cell killing ${ }^{11}$. To measure cytotoxic activity, control and treated CD8+T cells were co-cultured with CFSE-labelled allogeneic target cells, and the number of dead cells quantified by time-lapse imaging as described before $^{11}$. Based on our earlier studies for optimal killing, we selected an Effector:Target ratio of 1:1 and measured average cell killing during the first $6 \mathrm{~h}$ in culture. As seen in Fig. 1a-c, in representative time-course studies, relative to target cells alone, we detected a significant increase in dead target cells in the presence of allogeneic EM CD8+T cells. Moreover, when CD8+T cells were pretreated with $\mathrm{E}_{2}$ (Fig. 1a) or TGF $\beta$ (Fig. 1c), but not $\mathrm{P}$ (Fig. 1b), cell killing was markedly reduced. Figure $1 \mathrm{~d}-\mathrm{f}$ indicates the effect of hormones and TGF $\beta$ treatment on cytotoxicity measured both as total number of dead cells and as fold change in dead target cell numbers, the latter being done to compare experiments with different background mortalities of target cells alone. Consistent with our representative findings, relative to controls, $E_{2}$ (Fig. 1d), and TGF $\beta$ (Figs. 1f), but not P (Fig. 1e), significantly reduced cell killing. Figure $1 \mathrm{f}$ confirms our earlier results ${ }^{11}$ that CD8+T cell cytotoxic activity is significantly reduced following TGF $\beta$ treatment of EM CD8+T cells.

EM CD8+T cell expression of perforin and granzyme $A$ is inhibited by $E_{2}$. To identify the underlying mechanisms involved in suppression of cytotoxic $T$ cell activity, we evaluated the expression of perforin, granzyme A (GZA) and granzyme B (GZB) following preincubation of CD8+T cells with $\mathrm{E}_{2}$ or P. EM tissues were digested to obtain mixed cell suspensions and stained for intracellular cytotoxic molecules prior to analysis by flow cytometry as previously described ${ }^{11}$. Figure $2 \mathrm{a}$ contains representative histogram overlays of CD8+T cells for perforin, GZA and GZB indicating the downward shift in expression of perforin and GZA in response to $E_{2}$ but not $P$. Analysis of five separate experiments with different subjects (Fig. $2 b$ ), demonstrated that $E_{2}$ significantly reduced the intracellular content (MFI) of perforin and GZA in CD8+T cells. In contrast, $\mathrm{E}_{2}$ had no significant effect on GZB. Hormone treatment also affected the percentage of cells expressing cytotoxic molecules, as seen in Fig. 2c, with a significant decrease in the percentage of cells positive for perforin and GZA cells following incubation with $\mathrm{E}_{2}$. Overall, these studies demonstrate that $\mathrm{E}_{2}$ decreases the expression of perforin and GZA in EM CD8+T cells, which correlates with reduced cell cytotoxicity. Further, it indicates that these changes are hormone specific given that $\mathrm{P}$ had no effect on either perforin, GZA, and GZB intracellular expression or the percentage of positive cells.

EM CD103+and CD103- CD8+T cell expression of perforin and granzyme $A$ is inhibited by estradiol. In previous studies, we demonstrated that human EM CD8+T cells consist of tissue resident cells and non-resident CD8+T cells that are CD103+and CD103-, respectively ${ }^{8,11}$. When cytotoxicity was compared between CD103+and CD103-CD8+T cells, direct cytotoxic activity and expression of cytotoxic molecules was lower in CD103+compared to CD103-T cells ${ }^{11}$. Therefore, in this study we explored whether the observed effects of $\mathrm{E}_{2}$ in reducing cytotoxic molecule expression were due to effects on both CD103+and CD103-T 
a

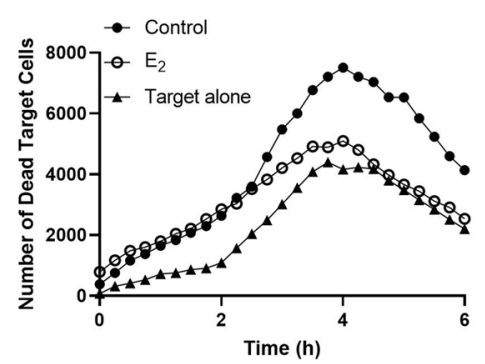

d

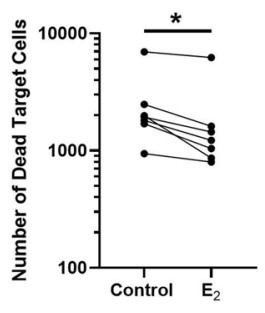

b

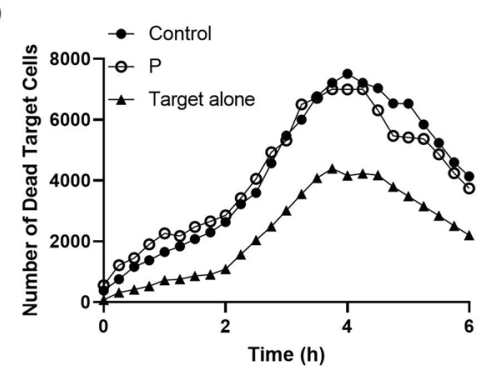

e

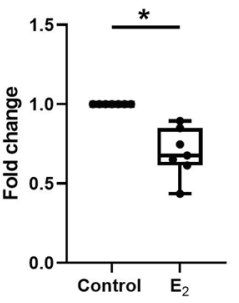

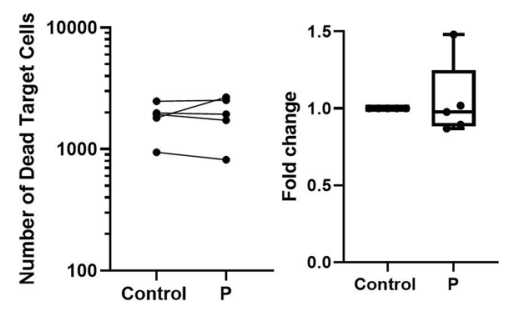

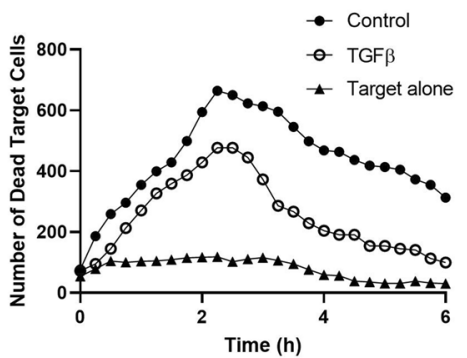

f

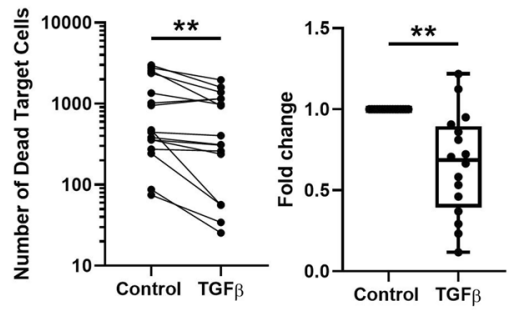

Figure 1. Effect of $\mathrm{E}_{2}, \mathrm{P}$ and TGF $\beta$ on endometrial $\mathrm{CD} 8+\mathrm{T}$ cells cytotoxicity. Purified endometrial CD8+T cells (effector cells, E) were pre-treated with $\mathrm{E}_{2}\left(5 \times 10^{-8} \mathrm{M}\right), \mathrm{P}\left(1 \times 10^{-7} \mathrm{M}\right)$ for $48 \mathrm{~h}$ or TGF $\beta(10 \mathrm{ng} / \mathrm{ml})$ for $2 \mathrm{~h}$ before co-culture with CFSE-stained allogeneic blood CD4+T cells (target cells, T) using a E:T ratio of 1:1. Cytotoxicity was measured over time by using quantitative time-lapse microscopy. Representative time-course of the kinetics of cytotoxicity over a period of $6 \mathrm{~h}$ in the absence (control) or presence of $E_{2}(\mathbf{a}), \mathrm{P}(\mathbf{b})$ and TGF $\beta(\mathbf{c})$. Target alone are allogeneic blood $\mathrm{CD} 4+\mathrm{T}$ cells. Comparison of $\mathrm{E}_{2}(\mathbf{d}, \mathrm{n}=7), \mathrm{P}(\mathbf{e}, \mathrm{n}=5)$ and TGF $\beta(\mathbf{f}, \mathrm{n}=16)$ treatment in the mean number of dead target cells (left graph) and fold change in the mean number of dead target cells after $\mathrm{E}_{2}, \mathrm{P}$ and TGF $\beta$ treatment compared to control (right graph). Each dot represents a different patient. Min to $\operatorname{Max}\left(\mathbf{d}-\mathbf{f}\right.$, right graph) are shown. ${ }^{\star} P<0.05$; ${ }^{*} P<0.01$; Wilcoxon matched-pairs signed rank test.

cell populations. Mixed cell suspensions from EM tissues were incubated with $\mathrm{E}_{2}$ for $48 \mathrm{~h}$ prior to measuring granular content by flow cytometry. Figure 3a shows a representative example of the content of perforin, GZA and GZB before and after treatment with estradiol. As shown in Fig. 3b, using matched samples from multiple patients, $\mathrm{E}_{2}$ significantly suppressed the content of perforin and GZA (MFI) in both tissue resident (CD103+) and non-resident (CD103-) CD8+T cells. In contrast, $\mathrm{E}_{2}$ had no effect on GZB. Interestingly, as seen in Fig. 3c, $\mathrm{E}_{2}$ reduced the percent positive $\mathrm{CD} 103+$ and $\mathrm{CD} 103-\mathrm{CD} 8+\mathrm{T}$ cells containing perforin but had no effect on the percentage of cells that were GZA or GZB positive. These findings suggest that $\mathrm{E}_{2}$ regulates both CD103+and CD103-CD8+T cells and that suppression of the levels of cytotoxic molecules is unique in that each of the cytotoxic responses to $\mathrm{E}_{2}$ are separate and distinct. This is consistent with our previous results that menopausal status equally affects resident and non-resident $\mathrm{T}$ cells ${ }^{11}$, suggesting that tissue residency does not modify sensitivity to hormonal control.

Perforin, granzyme A and B Content in EM CD8+T Cells is suppressed by TGF $\beta$. Next, we investigated the underlying mechanisms of TGF $\beta$-mediated cytotoxicity suppression. CD8+T cells in mixed cell suspensions were incubated with TGF $\beta$ prior to perforin, GZA, and GZB analysis by flow cytometry at $48 \mathrm{~h}$. As seen in the histograms (Fig. 4a) and analyses of intracellular content (Fig. 4b), TGF $\beta$ significantly reduced the concentration of all three intracellular cytotoxic molecules. In our patients we observe a wide range of perforin expression from 0.5 to $32.6 \%$ as shown in this study and in our previous publication ${ }^{11}$. The representative plots presented in Figs. 2 and 4 are from two different patients. Figure 2 is from a patient with low perforin expression, while Fig. 4 is from a patient with high perforin expression. These profiles are examples that reflect the range in expression profiles between patients. We also found that TGF $\beta$ reduced the percentage of total CD8+T cells that were perforin positive, but had no effect on the percentage of cells expressing GZA and GZB (Fig. 4c). We next investigated the effect of TGF $\beta$ on cytotoxic molecules in CD103+and CD103-CD8+T cell compartments (Fig. 5a). As seen in Fig. 5b, TGF $\beta$ significantly reduced the expression of perforin, GZA and GZB within both $\mathrm{CD} 103$ +and CD103-CD8+T cell populations. Interestingly, TGF $\beta$ reduced the number of perforin positive cells but had no effect on cells positive for GZA or GZB (Fig. 5c).

Progesterone increases the basolateral secretion of TGF $\beta$ by polarized EM epithelial cells. In addition to their directs effects, sex hormones are known to indirectly regulate immune cells by acting on adjacent cells in the tissue environment. TGF $\beta$ is known to be synthesized and secreted by EM epithelial cells and stromal cells from the uterus ${ }^{18,19}$. Our studies in a rodent model demonstrated that polarized EM epithelial cells preferentially secrete biologically active TGF $\beta$ into the basolateral compartment ${ }^{18}$. Therefore, we analyzed TGF $\beta$ production by polarized human EM epithelial cells. As seen in Fig. 6a, TGF $\beta$ was secreted constitutively by polarized epithelial cells with preferential release basolaterally, in the direction of underlying tissues. Since 


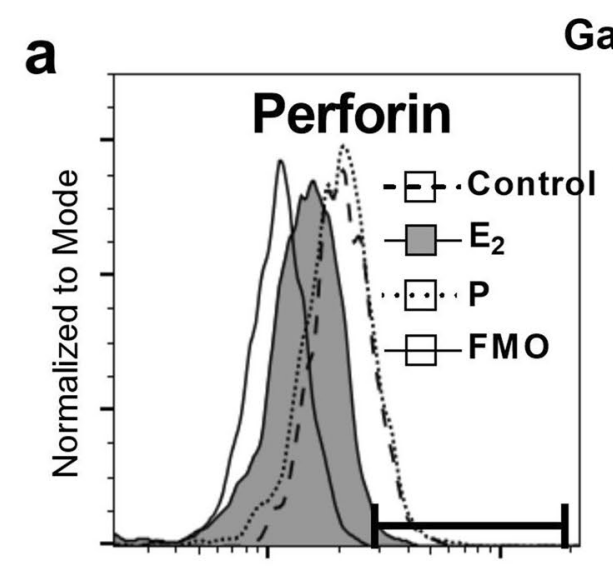

Gated on CD45+CD3+CD4-CD8+

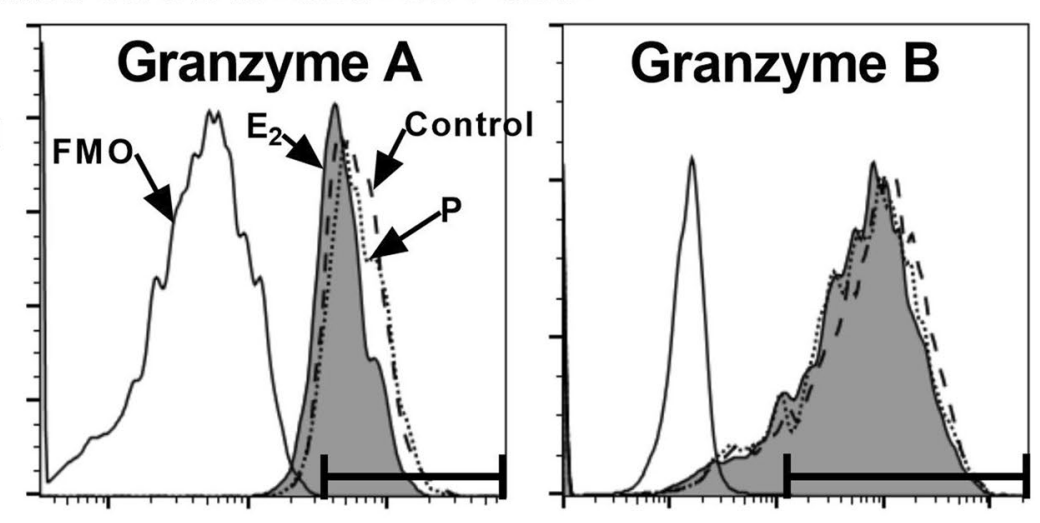

b
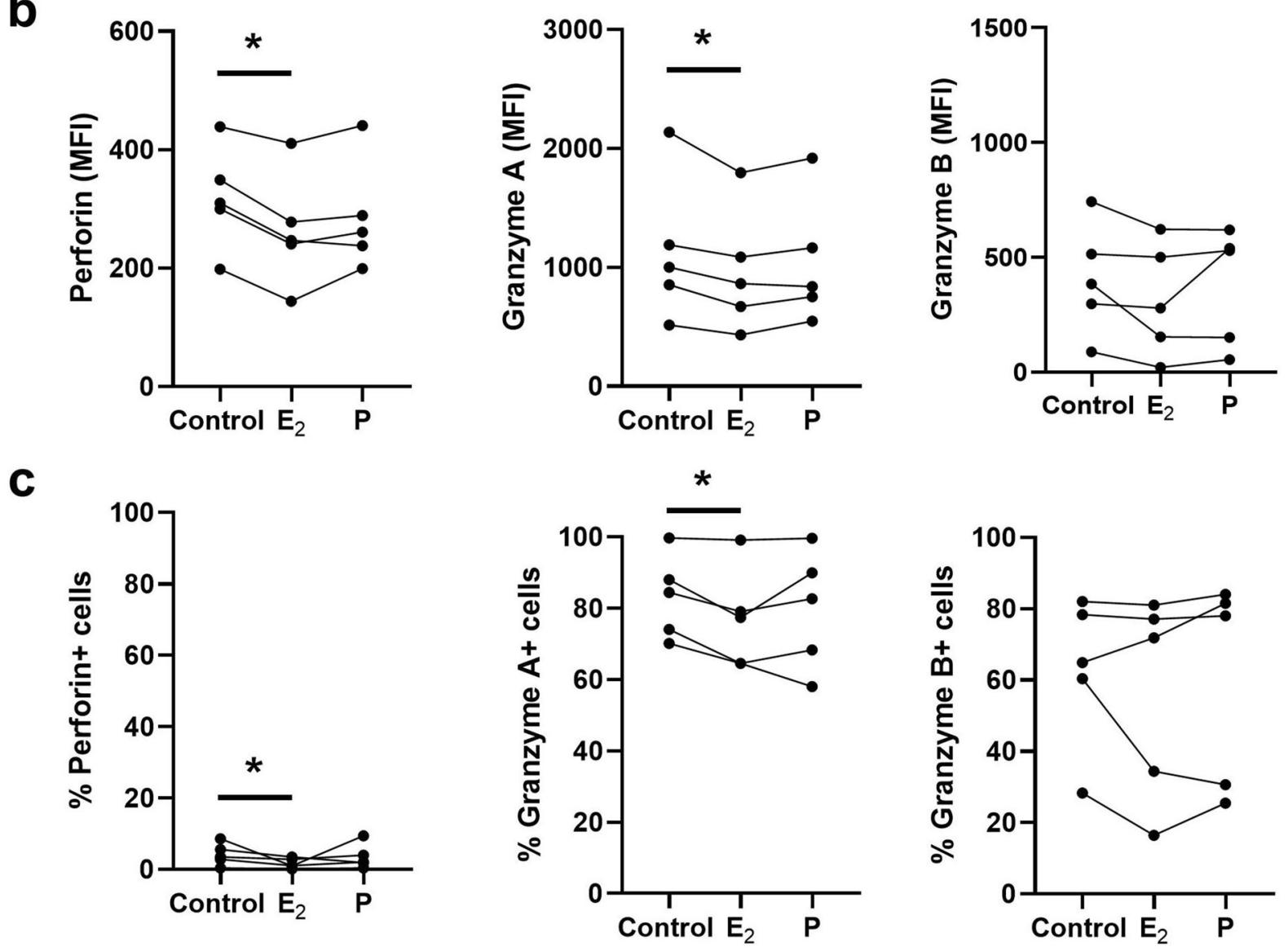

Figure 2. Effect of $E_{2}$ and $P$ on intracellular cytotoxic molecules in endometrial CD8+T cells. Mixed cell suspensions from endometrial tissues were pre-treated with $\mathrm{E}_{2}\left(5 \times 10^{-8} \mathrm{M}\right), \mathrm{P}\left(1 \times 10^{-7} \mathrm{M}\right)$ for $48 \mathrm{~h}$ and stained for the intracellular cytotoxic molecules perforin, granzyme A and granzyme B for analysis by flow cytometry. (a) Representative histograms of intracellular perforin (left), granzyme A (middle) and granzyme B (right) expression in endometrial CD8+T cells treated with $\mathrm{E}_{2}$ and $\mathrm{P}$. Gate boundaries (horizontal line) were set by fluorescence minus one (FMO) to indicate the gating of positive cells. (b) Median fluorescence intensity (MFI) of perforin (left), granzyme A (middle), granzyme B (right) and (c) percentage of perforin+ (left), granzyme $\mathrm{A}+$ (middle), granzyme $\mathrm{B}+$ (right) in endometrial CD8+T cells following incubation with $\mathrm{E}_{2}$ and $\mathrm{P}$. Each dot represents a different patient $(\mathrm{n}=5) .{ }^{\star} P<0.05$; Friedman test with Dunn's multiple comparisons test.

we have previously demonstrated that human polarized epithelial cells are hormonally responsive to $\mathrm{E}_{2}{ }^{21}$, we hypothesized that $\mathrm{E}_{2}$ might increase TGF $\beta$ secretion by epithelial cells as a secondary mechanism for regulating $\mathrm{CD} 8+\mathrm{T}$ cell cytotoxic activity. To test this, polarized EM epithelial cells were grown to confluence and incubated 
a

\section{Gated on CD45+CD3+CD4-CD8+}

$\mid$
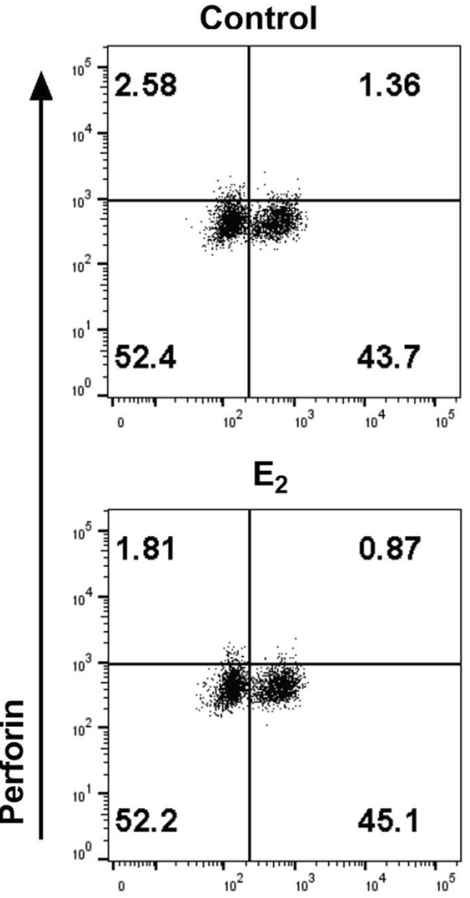

CD103

b

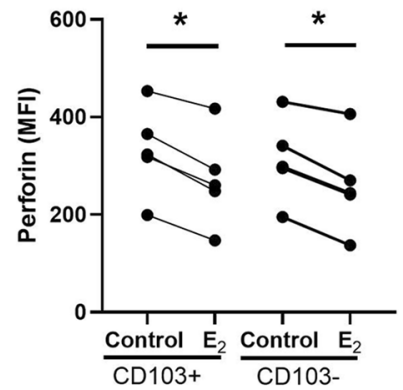

C

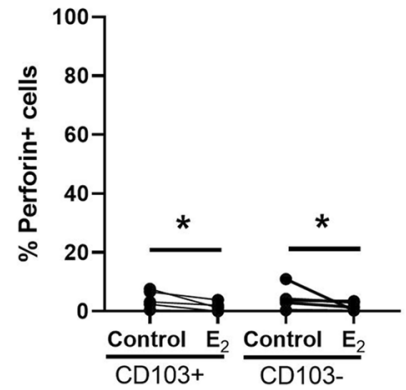

Control
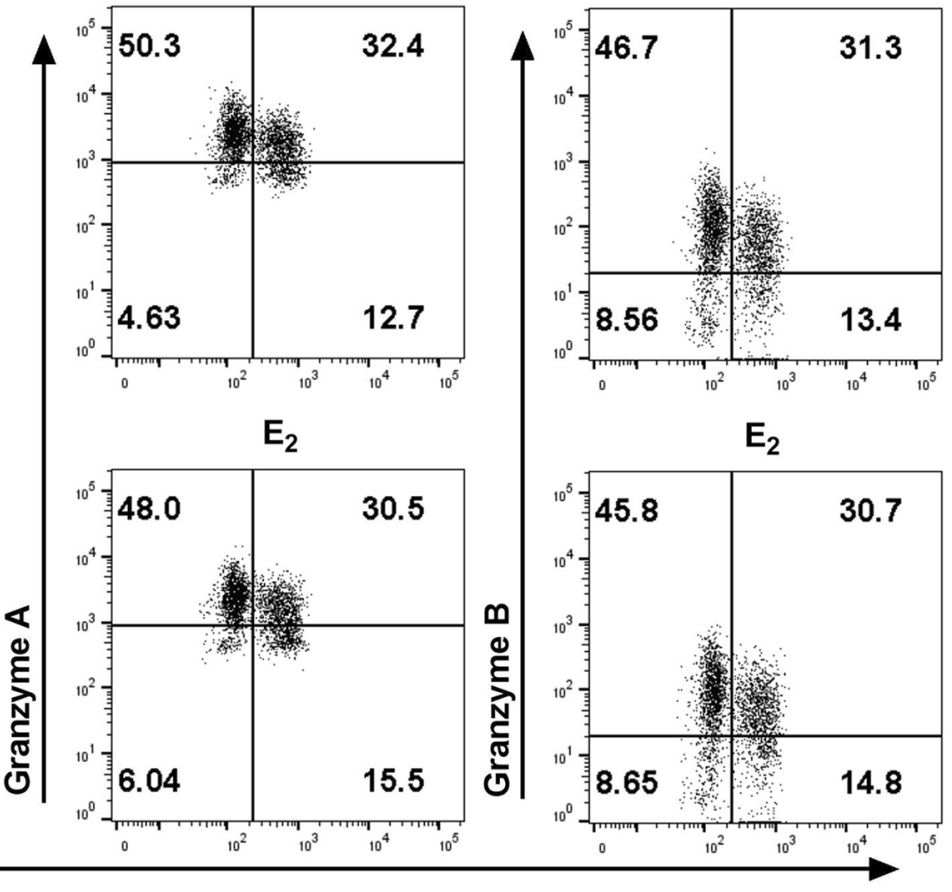

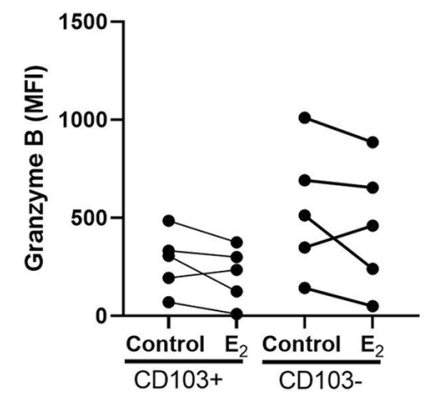

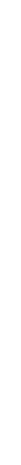


a Gated on CD45+CD3+CD4-CD8+
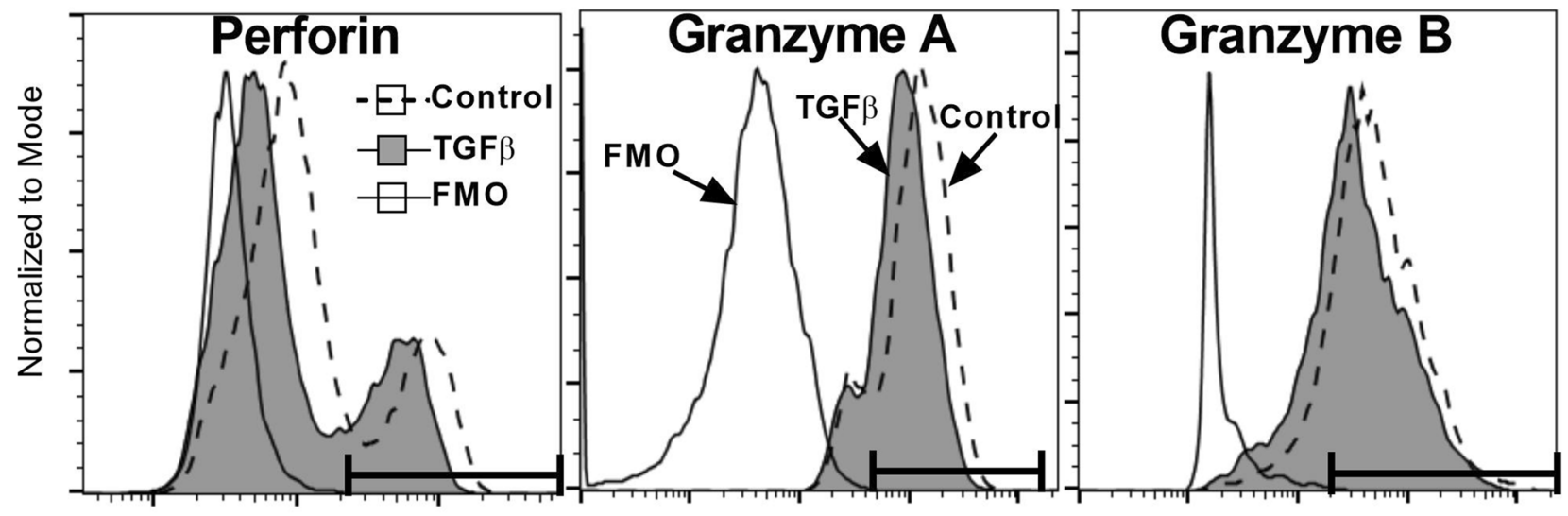

b
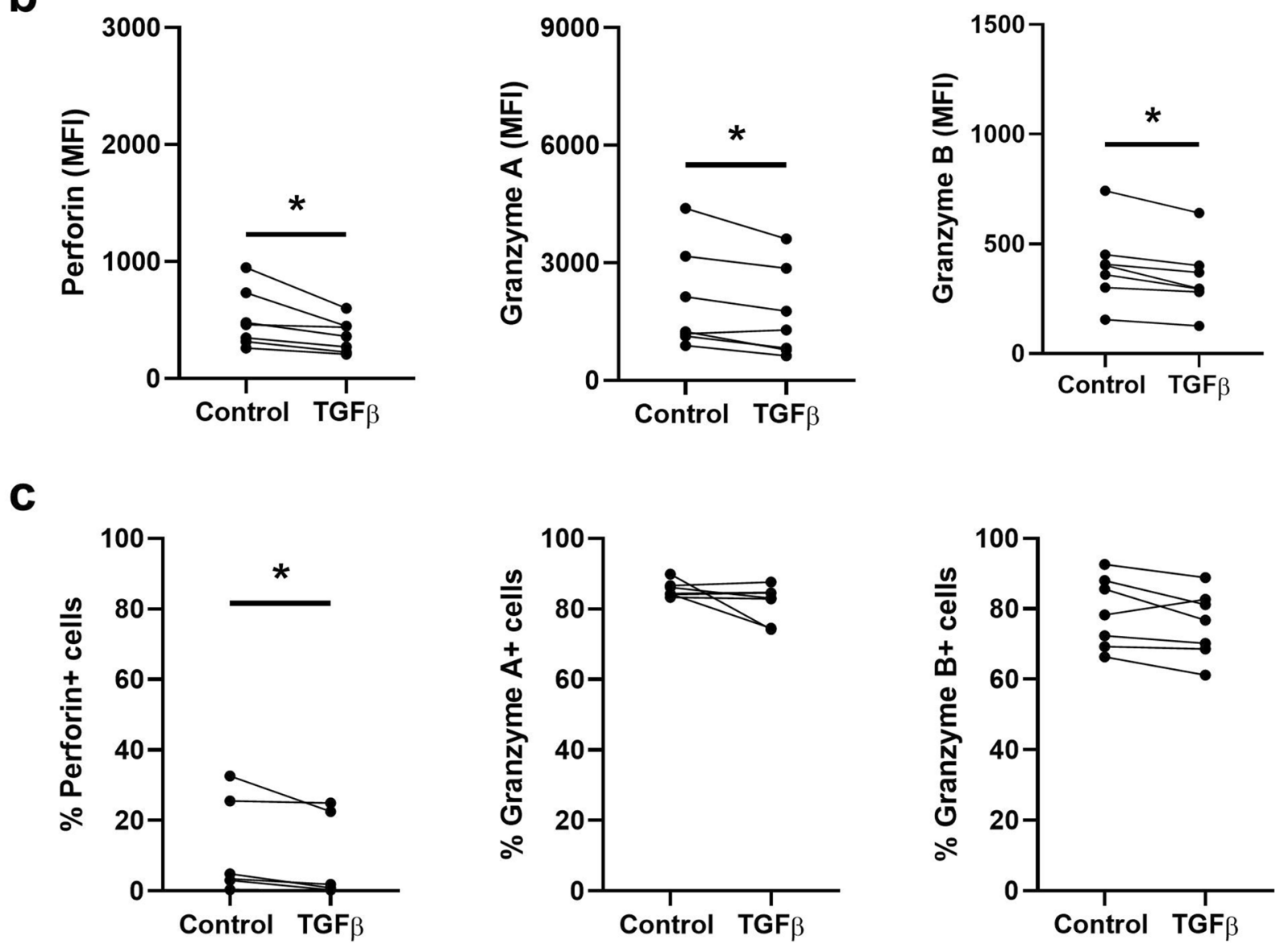

Figure 4. Effect of TGF $\beta$ on intracellular cytotoxic molecules in endometrial CD8+T cells. Mixed cell suspensions from endometrial tissues were pre-treated with TGF $\beta(10 \mathrm{ng} / \mathrm{ml})$ for $48 \mathrm{~h}$ and stained for the intracellular cytotoxic molecules perforin, granzyme A and granzyme B for analysis by flow cytometry. (a) Representative histograms of intracellular perforin (left), granzyme A (middle) and granzyme B (right) expression in endometrial CD8+T cells treated with TGF $\beta$. Gate boundaries (horizontal line) were set by fluorescence minus one (FMO) to indicate the gating of positive cells. (b) Median fluorescence intensity (MFI) of perforin (left), granzyme A (middle), granzyme B (right) and (c) percentage of perforin+ (left), granzyme $\mathrm{A}+$ (middle), granzyme $\mathrm{B}+$ (right) in endometrial CD8+T cells following incubation with TGF $\beta$. Each dot represents a different patient $(n=7) .{ }^{*} P<0.05$, Wilcoxon matched-pairs signed rank test.

with $\mathrm{E}_{2}$ or $\mathrm{P}$ for $48 \mathrm{~h}$ prior to collection of basolateral media. Unexpectedly, as shown in a representative experiment (Fig. 6b), we found that $P$ increased the basolateral secretion of TGF $\beta$ relative to controls and that $E_{2}$ had no effect on TGF $\beta$ production. To more fully analyze this response, we normalized the data from 6 experiments to express TGF $\beta$ production as the fold change relative to control cells, to compare experiments with different 
a Gated on CD45+CD3+CD4-CD8+

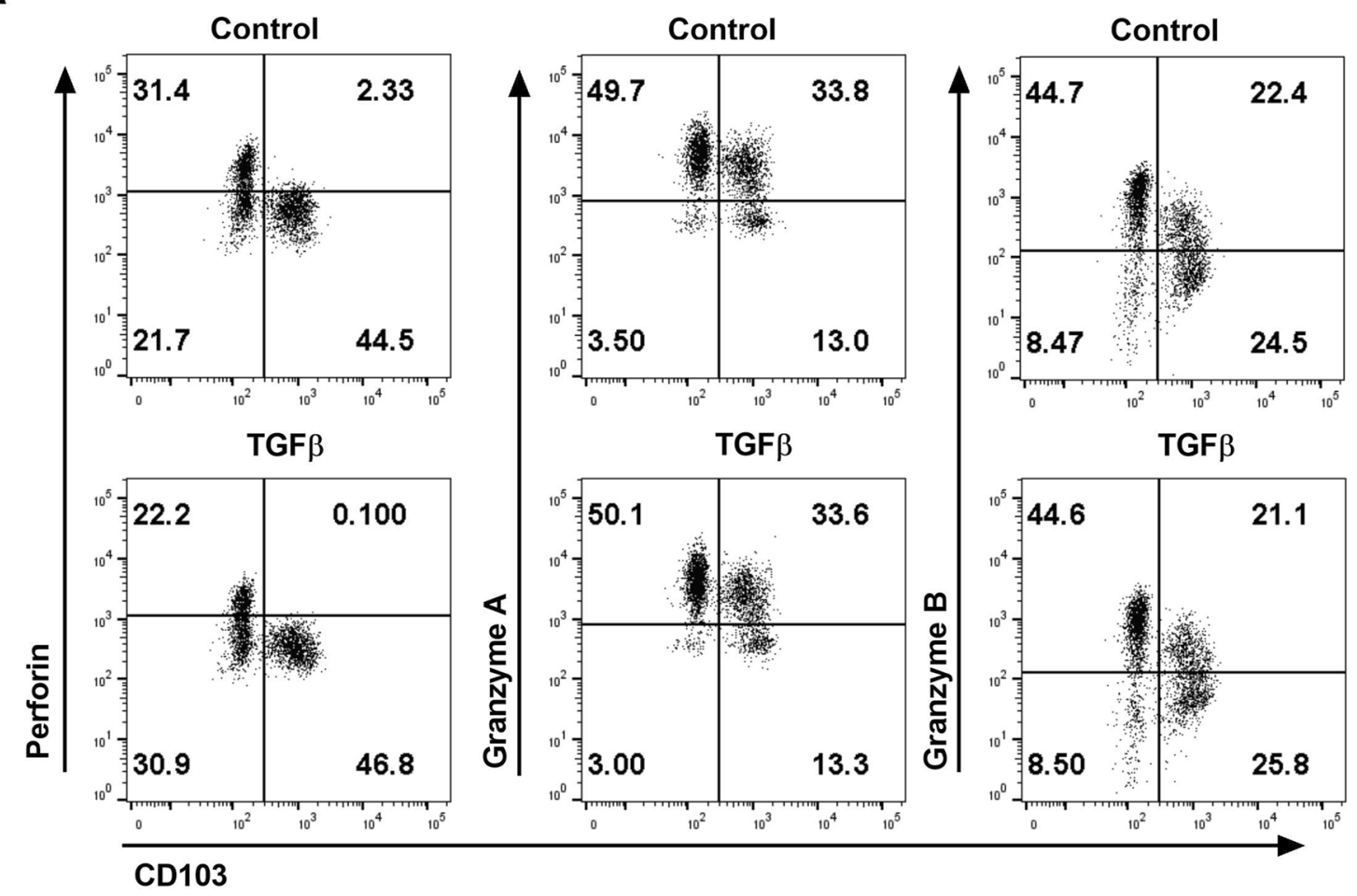

b
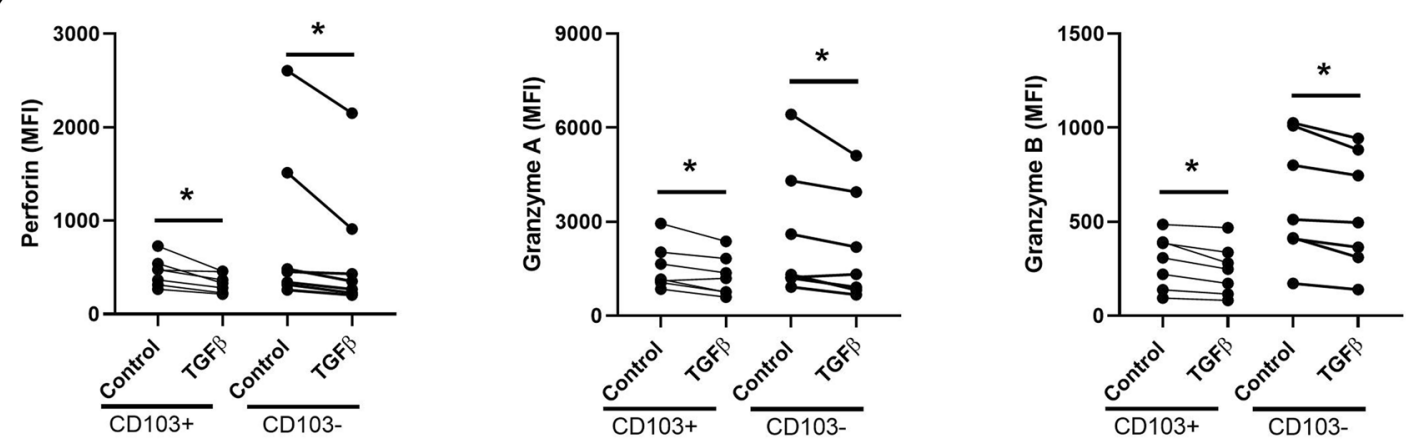

C
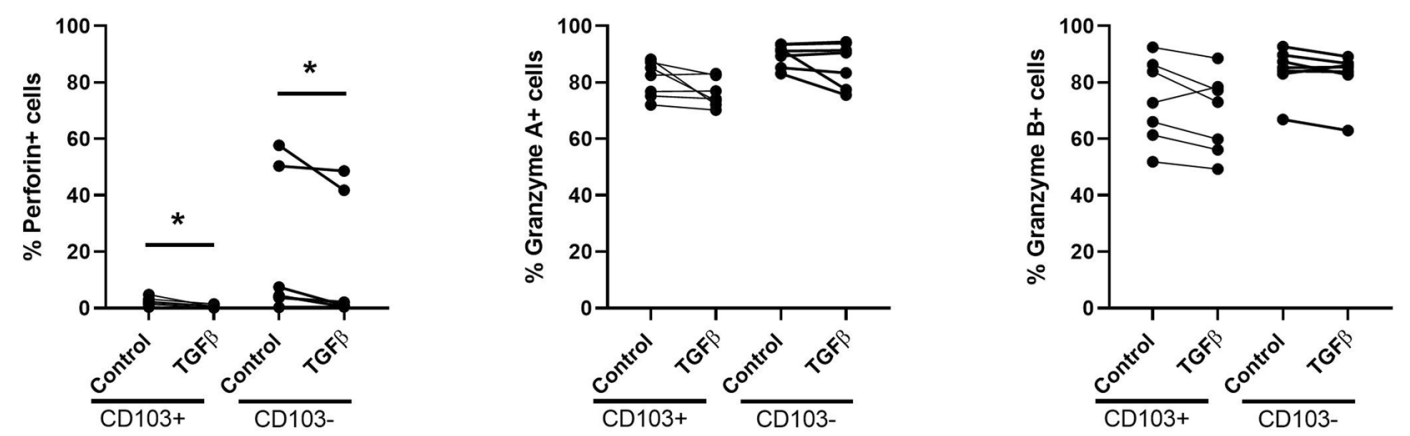

Figure 5. Effect of TGF $\beta$ on intracellular cytotoxic molecules in endometrial CD103+ and CD103-CD8+T cells. Mixed cell suspensions from endometrial were pre-treated with TGF $\beta(10 \mathrm{ng} / \mathrm{ml})$ for $48 \mathrm{~h}$ and stained for the intracellular cytotoxic molecules perforin, granzyme A and granzyme B for analysis by flow cytometry. (a) Representative dot plots of intracellular perforin (left), granzyme A (middle) and granzyme B (right) expression in endometrial CD103+and CD103-CD8+T cells treated with TGF $\beta$. Top row shows control group (without TGF $\beta$ ) and bottom row shows TGF $\beta$ treated group. (b) Median fluorescence intensity (MFI) of perforin (left), granzyme A (middle), granzyme B (right) and (c) percentage of perforin+ (left), granzyme A+ (middle), granzyme $\mathrm{B}+$ (right) in endometrium CD103+ and CD103-CD8+T cells following incubation with TGF 3 . Each dot represents a different patient $(n=7) .{ }^{\star} P<0.05$; Friedman test with Dunn's multiple comparisons test. 
a

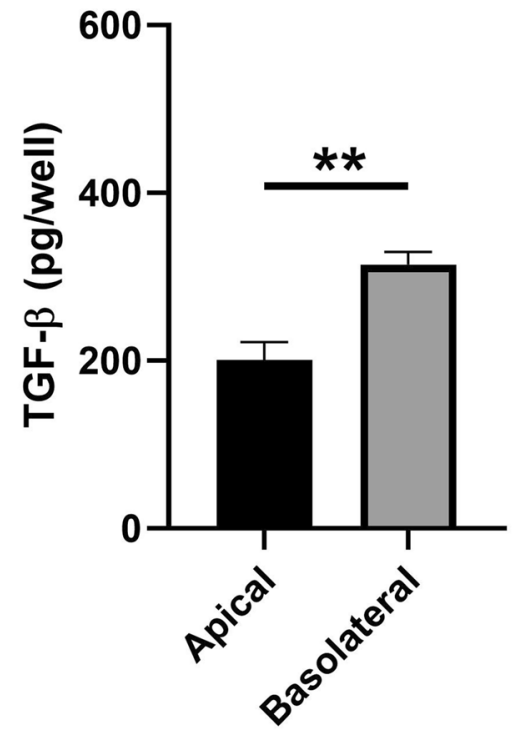

b

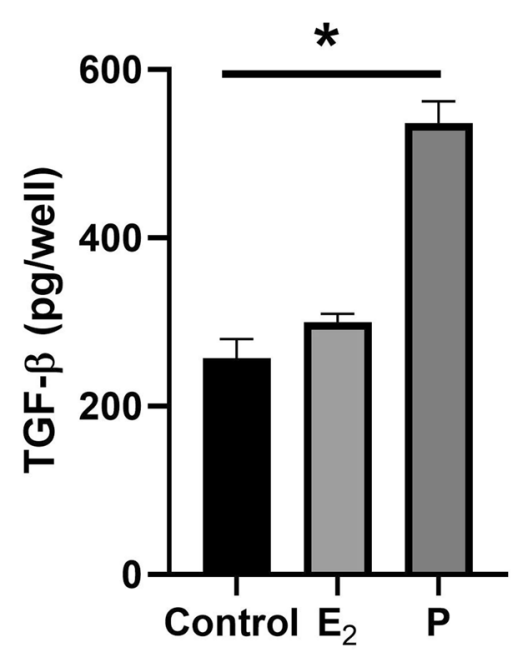

C

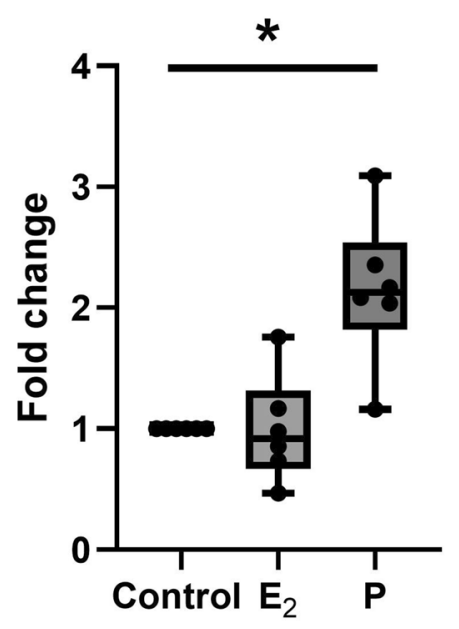

Figure 6. Constitutive production and regulation of TGF $\beta$ secretion in endometrial epithelial cells. Endometrial epithelial cells were isolated and cultured until confluence and high transepithelial resistance was reached. Polarized endometrial epithelial cells were treated with $\mathrm{E}_{2}\left(5 \times 10^{-8} \mathrm{M}\right)$ or $\mathrm{P}\left(1 \times 10^{-7} \mathrm{M}\right)$ for $48 \mathrm{~h}$. Apical and basolateral conditioned media (CM) were collected and assayed total TGF $\beta$ by ELISA. (a) Level of total TGF $\beta$ secreted following $48 \mathrm{~h}$ accumulation of constitutive apical and basolateral $(n=14)$. (b) Representative experiment showing the basolateral secretion of TGF $\beta$ by polarized endometrial epithelial cells following treatment with $\mathrm{E}_{2}$ or P for $48 \mathrm{~h}$. (c) Graph represents the fold change in total TGF $\beta$ in basolateral CM following $\mathrm{E}_{2}$ or P treatment compared with untreated controls $(\mathrm{n}=6)$. The mean and SEM (a and $\left.\mathbf{b}\right)$ and Min to Max $(\mathbf{c})$ are shown. ${ }^{\star} P<0.05 ;{ }^{\star *} P<0.01$; Wilcoxon matched-pairs signed rank test (a) and Friedman test with Dunn's multiple comparisons test (b and $\mathbf{c})$.

secretion backgrounds by control cells. As shown in (Fig. 6c), following normalization, $\mathrm{P}$ but not $\mathrm{E}_{2}$ consistently stimulated the secretion of TGF $\beta$ by EM epithelial cells. Overall, these studies suggest that during the secretory phase menstrual cycle, under the influence of progesterone, EM epithelial cells secrete increased amounts of TGF $\beta$ basolaterally into the tissue compartment to suppress CD8+T cell cytolytic activity.

\section{Discussion}

Our study demonstrates that $\mathrm{E}_{2}$ and TGF $\beta$ directly suppress EM CD8+T cell cytotoxic activity by downregulating intracellular perforin, GZA, or GZB expression. Further, we demonstrate that whereas $\mathrm{E}_{2}$ acts directly on CD8+T cells to suppress killing, $\mathrm{P}$ has no direct effect. However, P upregulates TGF $\beta$ secretion by EM epithelial cells, which could represent an indirect mechanism of control of cytotoxic activity in vivo. Overall, as depicted in Fig. 7, our findings demonstrate direct and indirect hormone-dependent mechanisms in the human endometrium able to suppress CD8+T cell cytolytic capacity in premenopausal women during the secretory phase of the menstrual cycle, without which successful implantation and pregnancy would be unlikely to occur.

$\mathrm{CD} 8+\mathrm{T}$ cells are key effector cells for immune protection, but their function in the endometrium is tightly regulated to avoid rejection of the semi-allogeneic fetus ${ }^{1,24}$. Our previous studies demonstrate that EM CD8+T cell cytotoxic activity is suppressed in premenopausal women compared to postmenopausal women, particularly during the secretory phase of the menstrual cycle, suggesting that sex hormones are key regulators of CD8+T cell cytotoxicity $^{10,11}$. However, the direct effect of sex hormones in suppression of cytotoxic function of EM CD8+T cells had never been addressed before. Therefore, we investigated whether sex hormones directly contribute to the suppression of CD8+T cell cytotoxic activity seen in premenopausal women.

We found that $\mathrm{E}_{2}$ directly suppresses cytotoxic activity of EM CD8+T cells, and that the reduction in killing capacity is due to decreased expression of the cytotoxic molecules perforin and GZA in CD8+T cells. In contrast to our studies which showed no effect of $E_{2}$ on GZB expression, Navarro et al. ${ }^{14}$ found that $\mathrm{E}_{2}$ increased the expression of GZB in blood. Differences observed are most likely due to their use of buffy-coat blood suspension containing CD8+T cells that were retrovirally transduced and activated, whereas we used purified EM CD8+T cells without any in vitro activation stimulus to measure the effects of $\mathrm{E}_{2}$. Furthermore, to test GZB production, they used a preparation of total T cells, containing both CD4+and CD8+T cells, while we used purified CD8+T cells. Whether activation status alters EM CD8+T cell responsiveness to $\mathrm{E}_{2}$ remains to be determined.

In contrast to $\mathrm{E}_{2}$, we found that $\mathrm{P}$ had no direct effect on $\mathrm{EM} \mathrm{CD8+T}$ cell cytotoxic activity or cytotoxic granule content. This lack of effect is probably due to the previously reported absence of nuclear $\mathrm{P}$ receptors in $\mathrm{CD} 8+\mathrm{T}$ cells ${ }^{25}$ and contrasts with findings showing $\mathrm{P}$ changes in cytokine production and reduction in T-cell proliferation following $\mathrm{P}$ treatment of peripheral blood CD8+T cells, which the authors attributed to $\mathrm{P}$ membrane 


\section{Menstrual Cycle - Secretory Phase}

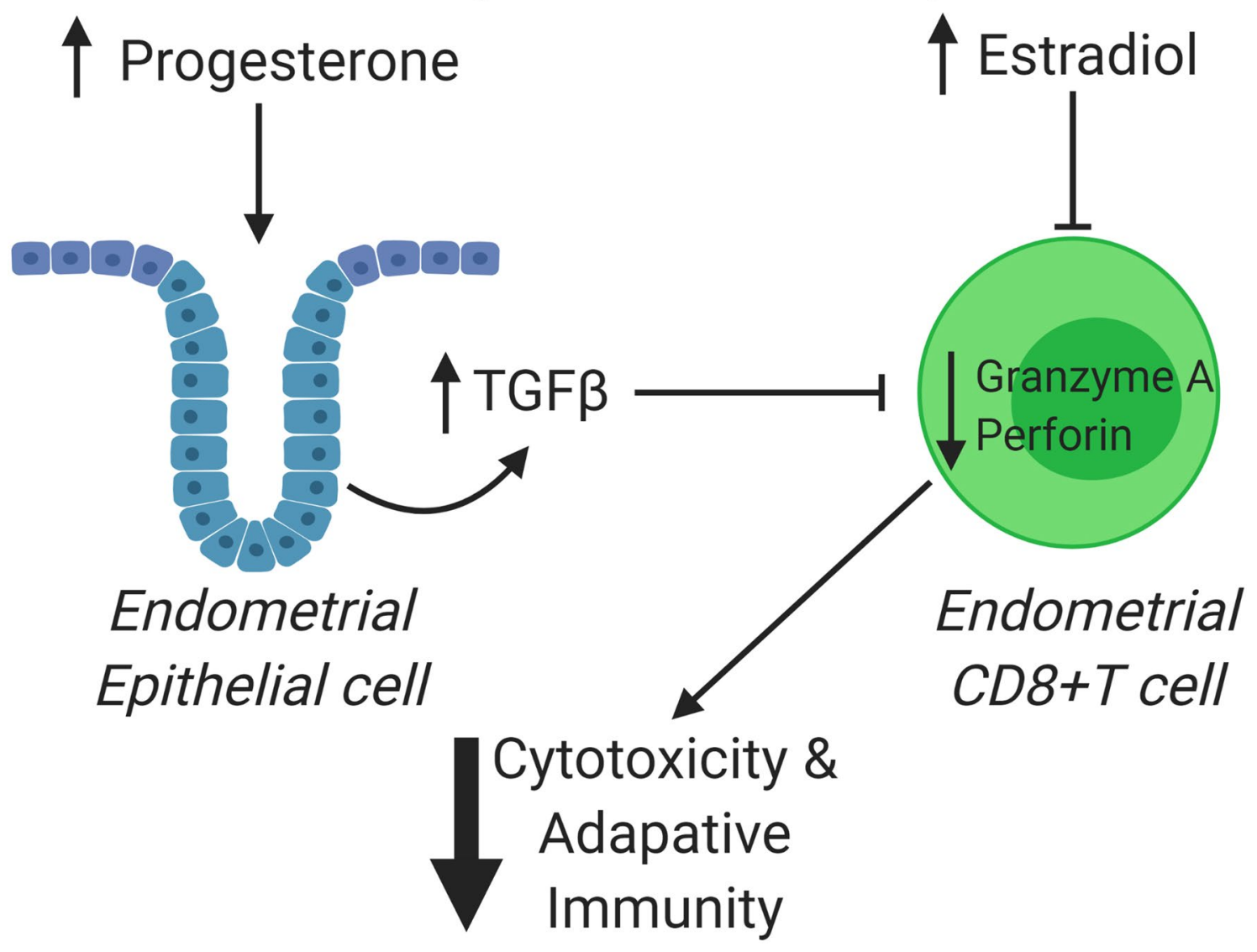

Figure 7. Estradiol and progesterone regulate CD8+T Cell cytotoxic activity in the endometrium during the secretory phase of the menstrual cycle. Schematic illustrating the complex relationship between sex hormones and CD8+T cells in the uterine endometrium during the secretory phase of the menstrual cycle ${ }^{1}$. Based on findings in this paper, $\mathrm{E}_{2}$ and $P$ play a central role in down-regulating adaptive immunity which optimizes the conditions for successful pregnancy ${ }^{22}$. Progesterone, for example, is synthesized by the ovary and peaks following ovulation in preparation for implantation. Our findings indicate that in response to $P$, but not $\mathrm{E}_{2}$, epithelial cells secrete TGF $\beta$ into the basolateral (tissue) compartment adjacent to CD8+T cells thereby reducing the intracellular content of perforin and GZA and cytolytic potential. Interestingly, $P$ had no direct effect of $\mathrm{CD} 8+\mathrm{T}$ cells. Accompanying the indirect effect of $P, \mathrm{E}_{2}$, which is known to peak at ovulation, decline and then rise throughout the secretory phase of the cycle ${ }^{23}$, through its direct effect on CD8+T cells, decreases perforin and GZA content thereby suppressing endometrial CD8+T cell adaptive activity.

receptors ${ }^{15}$. These differences suggest a finite specificity of $\mathrm{P}$ effects that are unique to the class of $\mathrm{P}$ receptor present or to functional differences between peripheral blood CD8+T cells and EM CD8+T cells.

Confirming our previous results, we found that EM cytotoxic function was rapidly suppressed by TGF $\beta$ after short-time treatment ${ }^{11}$. In the present study, we demonstrate that the suppressive effects of TFG $\beta$ are due to a reduction in the content of intracellular cytotoxic molecules (perforin, GZA and GZB). Given that in our experimental setting, cells were pre-treated with TGF $\beta$ for $2 \mathrm{~h}$ prior to cytotoxicity analysis and $48 \mathrm{~h}$ prior to intracellular cytotoxic molecule assessment, the underlying mechanism for rapid regulation of cytotoxic capacity remains unclear, and further investigation is warranted. Others have demonstrated that perforin and granzymes work synergistically to induce apoptosis in target cells recognized by CD8+T cells ${ }^{26}$. In addition to reductions in GZA and GZB, our findings show a reduction in both the levels of intracellular content of perforin as well as the percent positive cells. This is consistent with reports by others showing that cytotoxic function is suppressed by TGF $\beta$ through the reduction of perforin positive CD8+T cell numbers in the gastrointestinal tract ${ }^{17}$, and may indicate a general mechanism by which TGF $\beta$ controls cytotoxic activity of CD8+T cells in tissues. To the best of our knowledge, our findings are the first to demonstrate that $\mathrm{E}_{2}$ and TGF $\beta$ in culture reduce both the number of percent perforin positive CD8+T cells as well as the intracellular content of cytotoxic molecules of these cells.

We and others have demonstrated that TGF $\beta$ is produced by epithelial cells and fibroblasts from the FRT and under hormonal control in a rodent model $^{18,19}$. Interestingly, in the human, TGF $\beta$ mRNA expression in the endometrium is increased during the secretory phase of the menstrual cycle ${ }^{27}$, when EM CD8+T cells cytotoxic activity is maximally suppressed ${ }^{10,11}$. Our current study extends these findings by demonstrating that $\mathrm{P}$ acts directly on human EM epithelial cells to stimulate the secretion of TGF $\beta$. Interestingly, we found that $\mathrm{E}_{2}$ had no 
effect on epithelial cell TGF $\beta$ production, in contrast to our previous findings with the rodent model ${ }^{18}$. Consistent with our results, early studies in non-human primates also found that P increased mRNA of TGF $\beta 2$ in the endometrium $^{28}$. We have previously demonstrated broad effects of $E_{2}$ treatment on epithelial cells, including stimulation of intracellular genes, such as Cytosolic 5'-nucleotidase and P receptor ${ }^{29}$, and the secretion of SLPI along with other antimicrobial peptides with broad antimicrobial, antiviral and antifungal activity ${ }^{21,30}$. Our findings in the present study highlight the selectivity of hormonal effects on epithelial cells. Whether after its secretion in response to $\mathrm{P}$, other hormonally dependent steps further process TGF $\beta$ to increase biological activity remains to be determined ${ }^{31,32}$. Taken together, these findings suggest $E_{2}$ and $P$ precisely regulate adaptive immunity in the endometrium, by acting indirectly on epithelial cells to increase the production of TGF $\beta$.

The menstrual cycle is divided into a proliferative and a secretory phase, during which fertilization and implantation occurs. Others have shown that shortly after ovulation, during the secretory phase of the menstrual cycle, levels of $\mathrm{P}$ rise sharply and are sustained for 10-12 days ${ }^{33}$. Accompanying this increase in $\mathrm{P}$ is a secondary mid-secretory rise in $\mathrm{E}_{2}$ which is essential for implantation. In contrast, the proliferative phase of the cycle is dominated by $\mathrm{E}_{2}$. These hormonal changes control the cyclical remodeling of the endometrium in premenopausal women to optimize conditions for implantation. Based on our findings in the present study, we propose that in premenopausal women, $\mathrm{E}_{2}$ directly suppresses cytotoxic activity by EM CD8+T cells and reduces the intracellular content of perforin and GZA. With ovulation and unique to the endometrium, $\mathrm{P}$ induces the production of TGF $\beta$ by epithelial cells, which in turn acts on EM CD8+T cells to further suppress cytotoxic activity, and reduce the expression of perforin, GZA and GZB, achieving maximum suppression during the secretory phase of the menstrual cycle (Fig. 7).

In our previous studies, we demonstrated that cytotoxic activity is significantly increased in postmenopausal women $^{10,11}$. Following menopause, sex hormones levels $\left(\mathrm{E}_{2}\right.$ and $\left.\mathrm{P}\right)$ drop and remain low and constant. Our results in this study suggest that the reduction in sex hormones removes the direct and indirect suppressive mechanisms from EM CD8+T cells, resulting in an increase in cytotoxic activity and intracellular content of cytotoxic molecules, consistent with our previous findings ${ }^{11}$.

We and others have shown that CD8+T cells in the endometrium consist of both CD103+and CD103-T cells, likely representing tissue resident and non-resident memory $\mathrm{T}$ cells respectively. We demonstrated that cytotoxic activity and intracellular content of cytotoxic molecules was significantly higher in CD103-compared to $\mathrm{CD} 103+\mathrm{EM} \mathrm{CD} 8+\mathrm{T}$ cells ${ }^{11}$. Here we investigated whether the regulatory effects of $\mathrm{E}_{2}$ and TGF $\beta$ were preferential to either subset. We found that $\mathrm{E}_{2}$ and TGF $\beta$ affected CD103+and CD103-CD8+T cells equally and reduced the content of cytotoxic molecules in both subsets. These findings suggest that tissue-resident and non-resident $\mathrm{CD} 8+\mathrm{T}$ cells are equally susceptible to regulation by sex hormones, and that transition into tissue-residency status does not modify sensitivity to regulation by sex hormones and the tissue environment. Our results here are also in agreement with our previous observation that postmenopausal women tended to have decreased expression of GZB and increased expression of GZA compared to premenopausal women in both CD103-and $\mathrm{CD} 103+\mathrm{CD} 8+\mathrm{T}$ cells ${ }^{11}$. This would suggest that removal of sex hormone suppression after menopause induces changes in intracellular content of cytotoxic molecules in both cellular subsets.

Given that cytotoxic activity following menses returns during the follicular phase of the menstrual cycle ${ }^{10,11}$, suggests either that the absence of $\mathrm{P}$ and TGF $\beta$ reverses intracellular granular content and cytolytic activity or that a new population of CD8+T cells enters the endometrium. That cytolytic potential can be restored was suggested from studies in which in vitro neutralization of TGF $\beta$ partially restored perforin expression in gut CD8+T cells ${ }^{17}$. Moreover, using an inhibitor that blocks TGF $\beta$ signaling in EM CD8+T cells, we rescued cytotoxic activity in some samples ${ }^{11}$. Whether cytolytic potential is restored as hormone levels change with the menstrual cycle or the result of recruitment of CD8+T cells to the endometrium with the start of a new menstrual cycle remains to be determined. Further elucidation of EM cytotoxic T lymphocyte (CTL) activity and its implications for successful reproduction and protection against sexually transmitted diseases, including HIV, will provide essential information for the development of vaccines and immunotherapies targeted to the FRT.

Regarding study limitations, in addition to the mechanisms addressed in our study, alternative mechanisms of regulation of cytotoxic activity by sex hormones remain to be explored. For example, while we detected significantly lower levels of cytotoxic molecules following $\mathrm{E}_{2}$ treatment, whether the observed effects were due to direct actions of $E_{2}$ on the production of cytotoxic molecules or secondary to decreased activation status of $\mathrm{CD} 8+\mathrm{T}$ cells remains to be determined. Further, in addition to the perforin/granzyme pathway, the FAS/FASL pathway also mediates cell death ${ }^{34}$. In preliminary studies we have observed no modification of sFASL production by EM CD8+T cells after incubation with hormones under resting conditions. Further research is needed to address whether the FAS/FASL pathway is significantly modified by $\mathrm{E}_{2}$ after $\mathrm{T}$ cell stimulation, and if so, the potential contribution of the FAS/FASL pathway to cytotoxic function of EM CD8+T cells.

Another important aspect not addressed in this study is the extent to which sex hormones modify degranulation of $\mathrm{T}$ cells. In previous studies, we demonstrated a significant increase in degranulation capacity of CD8+T cells from the FRT after menopause ${ }^{11}$, suggesting a potential implication of sex hormones in regulation of degranulation capacity. Future studies are needed to investigate the extent to which $\mathrm{E}_{2}$ and $\mathrm{P}$ directly modify degranulation of CD8+T cells. Furthermore, in addition to cytotoxic molecules, FRT CD8+T cells can secrete and array of cytokines and chemokines upon stimulation, including IFN $-\gamma$ and $\mathrm{TNFa}^{35}$. In preliminary studies, we observed no differences in secretion of IFN- $\gamma$ and TNFa in CD8+T cells treated with $\mathrm{E}_{2}$ or P under resting conditions; however, whether cytokine production after stimulation is modified by sex hormones remains to be addressed in future studies.

Although our study is focused on CD8+T cells, a full understanding of the regulation of cytotoxic activity in the FRT during the menstrual cycle will require the functional evaluation of CD4+T cells and NK cells. We have previously demonstrated decreased proportions of CD4+T cells in the EM from postmenopausal women ${ }^{9}$. However, whether $\mathrm{E}_{2}$ and $\mathrm{P}$ modify the presence and function of EM CD4+T cells throughout the menstrual 
cycle is unknown. Endometrial NK cells, which have overlapping cytotoxic functions with CD8+T cells, increase in numbers from approximately $3 \%$ of leukocytes in proliferative phase to $30 \%$ in secretory phase tissues ${ }^{36-38}$ where they surround the spiral arteries ${ }^{39}$, due to increased chemotaxis and proliferation. Whether sex hormones directly influence cytotoxic function of endometrial NK cells is unclear. Previous studies using peripheral blood NK cells have shown contradictory evidence of a menstrual cycle effect on cytotoxicity ${ }^{40,41}$. However, others have demonstrated that endometrial NK cells in the early proliferative phase have lower cytotoxicity compared to other stages of the menstrual cycle ${ }^{42}$. Together these findings suggest that sex hormones modulate cytotoxic activity of multiple cell types as part of a larger program to optimize conditions in the FRT for successful reproduction.

In conclusion, our study demonstrates two unique hormone-dependent regulatory mechanisms that regulate $\mathrm{CD} 8+\mathrm{T}$ cell cytotoxic function in the uterine endometrium, one which involves the direct effect of $\mathrm{E}_{2}$ and the other, the indirect effect of P-mediated epithelial cell production of TGF $\beta$. In response to $\mathrm{E}_{2}$ and TGF $\beta$, CD103+and CD103-CD8+T cell cytolytic potential is suppressed. These results are central to our understanding of hormonal regulation of cytotoxic activity during the menstrual cycle, during pregnancy and following menopause, and to the development of therapeutics for both the prevention and control sexually transmitted infections and gynecological cancers.

\section{Methods}

Study subjects. Studies were performed with Dartmouth College Institutional Review Board approval. All investigations were conducted according to the principles expressed in the Declaration of Helsinki and carried out with the approval to use discarded tissues from hysterectomies from the Committee for the Protection of Human Subjects (CPHS), Dartmouth-Hitchcock Medical Center, and with written informed consent obtained from the patients before surgery. Indications for surgery were benign conditions such as fibroids and prolapse (age from 31 to 82); tissue samples selected were distant from the sites of pathology and without pathological lesions as determined by a pathologist. Women were not on oral contraceptives before hysterectomy. Menopausal status was determined by a pathologist based on the histological evaluation of sections of the endometrium (endometrial dating). Post-menopausal status was characterized by an atrophic endometrium. Information regarding genital infections was not available. Blood Leuko Paks from women were obtained from our IRBapproved collection facility at Dartmouth-Hitchcock Medical Center. Blood donors were anonymous, no information regarding age or hormonal status was available and only female donors were used in this study.

Tissue processing. EM tissues were transferred to the laboratory immediately after surgery and processed as previously described ${ }^{8,9,43-45}$. Average tissue weight obtained was $2.6 \pm 2.0 \mathrm{~g}$. Tissues were rinsed with $1 \times$ HBSS (Hanks balanced salt solution) supplemented with phenol red, $100 \mathrm{U} / \mathrm{ml}$ penicillin, $100 \mu \mathrm{g} / \mathrm{ml}$ streptomycin (all Thermo Scientific Hyclone, Logan, UT), and $0.35 \mathrm{mg} / \mathrm{ml} \mathrm{NaCO}_{3}$ (Fisher Scientific, Pittsburgh, PA). Tissues were then minced under sterile conditions into 1-2 mm fragments and digested using an enzyme mixture containing $0.05 \%$ collagenase type IV (Sigma-Aldrich, St. Louis, MO) and 0.01\% DNAse (Worthington Biochemical, Lakewood, NJ) for $1 \mathrm{~h}$ at $37^{\circ} \mathrm{C}$. Type IV collagenase was selected based on preliminary studies to ensure non-cleavage of surface markers ${ }^{9,44}$. After digestion, cells were dispersed through a 250 - $\mu$ m nylon mesh screen (Small Parts, Miami Lakes, FL), washed, and resuspended in complete media consisting of DMEM/F12 medium without phenol red (Invitrogen Life Technologies, Carlsbad, CA) supplemented with 20 mM HEPES, 2 mM L-glutamine (Invitrogen Life Technologies, Carlsbad, CA), $50 \mathrm{mg} / \mathrm{mL}$ primocin (Invivogen, San Diego, CA, USA) and 10\% heat-inactivated defined Fetal Bovine Serum (FBS) (Hyclone, Logan, UT, USA). Epithelial cell sheets were separated from stromal cells by filtration through a $20-\mu \mathrm{m}$ mesh filter (Small Parts). Epithelial cell sheets were retained on the filter, while stromal cells passed through. Stromal cells were then washed, counted and dead cells removed using the Dead cell removal kit (Miltenyi Biotec, Auburn, CA) according to manufacturer instructions. The resulting mixed cell suspension, consisting of immune cells and stromal fibroblasts, was used for flow cytometric analysis and further CD8+T cells purification.

Isolation and culture of EM epithelial cells. Epithelial cell sheets were recovered from $20-\mu \mathrm{m}$ mesh filters by rinsing and backwashing the filter with complete medium, centrifuged at $500 \times g$ for 5 min and analyzed for cell number and viability. To establish a cell culture system of polarized human EM epithelial cells with both apical and basolateral compartments, EM epithelial cells were cultured in Matrigel matrix (BD Biosciences) coated Falcon cell culture inserts in 24-well companion culture plates (Fisher Scientific). Apical and basolateral compartments contained 300 and $500 \mu \mathrm{l}$ of complete medium, respectively, which was changed every 2 days. Tight junction formation of epithelial cell monolayers from EM was assessed by periodically measuring transepithelial resistance (TER) using an EVOM electrode and Voltohmmeter (World Precision Instruments, Sarasota, $\mathrm{FL})$, as described previously ${ }^{46-48}$.

Preparation of EM CD8+T cells. Following removal of dead cells from the filter pass through suspension of stromal cells, CD8+T cells were isolated using negative magnetic bead selection with the CD8+T cell isolation kit (Miltenyi Biotec) following instructions with minor modifications. This negative selection protocol delivers untouched CD3+CD8+T cells. Additionally, anti-fibroblast microbeads (Miltenyi Biotec) were added in combination with the microbeads supplied with the kit to ensure depletion of stromal fibroblasts present in the mixed cell suspension as described before ${ }^{9,11}$. After two rounds of negative selection, purity of the CD8+T cell population was higher than $90 \%$, with approximately $2 \%$ contamination with non-immune cells, $2 \%$ CD3- cells and $1-2 \%$ contamination with CD4+T cells ${ }^{11}$. The average number of total CD8+T cells recovered per gram of tissue was $2 \times 10^{5}$. Following isolation, purified CD8+T cells were resuspended in immune cell media consisting of X-VIVO 15 Media (Lonza, Walkersville, MD) supplemented with 10\% charcoal stripped human AB serum 
(Valley Biomedical, Winchester, VA) and co-cultured with $\mathrm{E}_{2}$ and/or P for $48 \mathrm{~h}$ or TGF $\beta$ (10 ng/ml, PeproTech Inc.) $)^{11,49}$ for $2 \mathrm{~h}$ prior to cytotoxicity assays.

Preparation of blood CD4+T cells. Blood CD4+T cells were purified using negative magnetic beads selection with the CD4+T cell isolation kit (Miltenyi Biotech) following isolation of PBMC by standard Ficoll density gradient centrifugation ${ }^{9,50}$. Freshly isolated blood CD4+T cells were stained with CFSE (Cell Division Tracker Kit; BioLegend) as recommended by the manufacturer. The cells were then resuspended in immune cell media as allogeneic target cells prior to cytotoxicity assays.

Hormone preparation. $\quad 17 \beta$-estradiol $\left(\mathrm{E}_{2}\right.$, Calbiochem, Gibbstown, $\left.\mathrm{NJ}\right)$ or progesterone (P, Calbiochem) was dissolved in $100 \%$ ethanol for an initial concentration of $1 \times 10^{-3} \mathrm{M}$, evaporated to dryness and suspended in epithelial cells complete media containing 10\% charcoal dextran-stripped FBS or immune cell complete media to a concentration of $1 \times 10^{-5} \mathrm{M}$. Further dilutions were made to achieve final working concentration, and cells were treated with $5 \times 10^{-8} \mathrm{M} \mathrm{E}_{2}$ and/or $1 \times 10^{-7} \mathrm{M} \mathrm{P}$. Both are standard hormone treatment concentrations used by our laboratory and each is within the physiological range of hormone concentration ${ }^{20}$. As a control, an equivalent amount of ethanol without dissolved hormone was initially evaporated.

Sex hormone treatment and TGF $\beta$ analysis of EM epithelial cells. Epithelial cells in culture were switched to complete media containing $10 \%$ of charcoal dextran-stripped FBS prior to hormone treatment. After $24 \mathrm{~h}$, the media was replaced, and cells were treated with hormone for $48 \mathrm{~h}$. Hormone $\left(\mathrm{E}_{2}\right.$ or $\left.\mathrm{P}\right)$ or ethanol control media was added to both the apical and basolateral compartments. After $48 \mathrm{~h}$ incubation, apical and basolateral conditional media $(\mathrm{CM})$ were collected and stored immediately at $-80^{\circ} \mathrm{C}$ prior to TGF $\beta$ ELISA (R\&D systems, Minneapolis, $\mathrm{MN}$ ) according to the manufacturer's recommendations.

Cytotoxicity assay. Purified and preincubation of CD8+T cells with $\mathrm{E}_{2}, \mathrm{P}$ or TGF $\beta$ were co-cultured with CFSE-stained blood CD4+T cells in immune cell media, at an Effector:Target ratio of 1:1, in 96 well plates. Cytotox red (IncuCyte Cytotox Red, Essen Bioscience) was added to the media to stain dead cells. Plates were imaged every 15 min using the IncuCyte Zoom system (Essen Bioscience), and dead target cells were automatically quantified over time as double green (CFSE) and red (Cytotox) stained cells ${ }^{11}$.

Flow cytometry. Mixed cell suspensions from EM tissues were treated with TGF $\beta, \mathrm{E}_{2}$ or $\mathrm{P}$ for $48 \mathrm{~h}$ prior to cell staining for flow cytometry analysis. For experiments in which intracellular cytotoxic molecules were analyzed, mixed EM CD8+T cells were examined by flow cytometry to identify CD103+and CD103- subsets as described previously ${ }^{11}$. Suspensions were stained for surface markers with combinations of the following antibodies: CD45-AF700, CD3-APC-Cy7, CD103-BV711 (BioLegend), CD4-PE-Cy5.5 (eBioscience, San Diego, CA), CD8-BUV395 (BD Bioscience). To detect of perforin, granzyme A (GZA) and granzyme B (GZB), following surface staining, cells were fixed and permeabilized with Cytofix/cytoperm kit (BD) according to instructions. Intracellular staining of perforin, granzyme A and B was done using combinations of the following antibodies: anti-human Perforin-PE/Dazzle, Granzyme A-AF647 (BioLegend) and Granzyme B-BV421 (BD Bioscience). Analysis was performed on BioRad ZE5 flow cytometers (BioRad) using Everest software, and data analyzed with FlowJo software version v10 (Tree Star, Inc. Ashland, OR, www.flowjo.com). Expression of surface and intracellular markers was measured by the percentage of positive cells and measured median fluorescence intensity (MFI).

Statistics. Data analysis was performed using the GraphPad Prism version 8.3.0 for Windows (GraphPad Software, San Diego, CA, www.graphpad.com). A two-sided $P$ value $<0.05$ was considered statistically significant. Comparison of two groups was performed with the non-parametric Wilcoxon matched-pairs signed rank test. Comparison of three or more groups was performed applying the non-parametric Friedman test with Dunn's multiple comparisons test.

Image generation. Figures 1 and 6 were created using GraphPad Prism version 8.3.0 for Windows (GraphPad Software, www.graphpad.com). Figures 2, 3, 4 and 5 were created using FlowJo software version v10 (www. flowjo.com) and GraphPad Prism version 8.3.0 for Windows (GraphPad Software, www.graphpad.com). Figure 7 was created using BioRender.com.

Ethics statement. The studies were performed with Dartmouth College Institutional Review Board approval. Approval to use discarded tissues from hysterectomies was obtained from the Committee for the Protection of Human Subjects (CPHS).

\section{Data availability}

The datasets generated for this study are available on request to the corresponding author.

Received: 1 October 2020; Accepted: 4 January 2021

Published online: 19 January 2021 


\section{References}

1. Wira, C. R., Rodriguez-Garcia, M. \& Patel, M. V. The role of sex hormones in immune protection of the female reproductive tract. Nat. Rev. Immunol. 15, 217-230. https://doi.org/10.1038/nri3819 (2015).

2. Critchley, H. O. D., Maybin, J. A., Armstrong, G. M. \& Williams, A. R. W. Physiology of the endometrium and regulation of menstruation. Physiol. Rev. 100, 1149-1179. https://doi.org/10.1152/physrev.00031.2019 (2020).

3. Khan, D. \& Ansar Ahmed, S. The immune system is a natural target for estrogen action: Opposing effects of estrogen in two prototypical autoimmune diseases. Front. Immunol. 6, 635. https://doi.org/10.3389/fimmu.2015.00635 (2015).

4. Kovats, S. Estrogen receptors regulate innate immune cells and signaling pathways. Cell. Immunol. 294, 63-69. https://doi. org/10.1016/j.cellimm.2015.01.018 (2015).

5. Wira, C. R., Fahey, J. V., Rodriguez-Garcia, M., Shen, Z. \& Patel, M. V. Regulation of mucosal immunity in the female reproductive tract: The role of sex hormones in immune protection against sexually transmitted pathogens. Am. J. Reprod. Immunol. 72, 236-258. https://doi.org/10.1111/aji.12252 (2014).

6. Givan, A. L. et al. Flow cytometric analysis of leukocytes in the human female reproductive tract: Comparison of fallopian tube, uterus, cervix, and vagina. Am. J. Reprod. Immunol. 38, 350-359 (1997).

7. Flynn, L. et al. Menstrual cycle dependent fluctuations in NK and T-lymphocyte subsets from non-pregnant human endometrium. Am. J. Reprod. Immunol. 43, 209-217. https://doi.org/10.1111/j.8755-8920.2000.430405.x (2000).

8. Rodriguez-Garcia, M., Fortier, J. M., Barr, F. D. \& Wira, C. R. Aging impacts CD103(+) CD8(+) T cell presence and induction by dendritic cells in the genital tract. Aging Cell https://doi.org/10.1111/acel.12733 (2018).

9. Rodriguez-Garcia, M., Barr, F. D., Crist, S. G., Fahey, J. V. \& Wira, C. R. Phenotype and susceptibility to HIV infection of CD4+ Th17 cells in the human female reproductive tract. Mucosal Immunol. 7, 1375-1385. https://doi.org/10.1038/mi.2014.26 (2014).

10. White, H. D. et al. $\mathrm{CD} 3+\mathrm{CD} 8+\mathrm{CTL}$ activity within the human female reproductive tract: Influence of stage of the menstrual cycle and menopause. J. Immunol. 158, 3017-3027 (1997).

11. Rodriguez-Garcia, M., Shen, Z., Fortier, J. M. \& Wira, C. R. Differential cytotoxic function of resident and non-resident CD8+ $\mathrm{T}$ cells in the human female reproductive tract before and after menopause. Front. Immunol. 11, 1096. https://doi.org/10.3389/ fimmu.2020.01096 (2020).

12. Staples, J. E. et al. Estrogen receptor alpha is necessary in thymic development and estradiol-induced thymic alterations. J. Immunol. 163, 4168-4174 (1999).

13. Lindberg, M. K. et al. Estrogen receptor alpha, but not estrogen receptor beta, is involved in the regulation of the OPG/RANKL (osteoprotegerin/receptor activator of NF-kappa B ligand) ratio and serum interleukin-6 in male mice. J. Endocrinol. 171, 425-433. https://doi.org/10.1677/joe.0.1710425 (2001).

14. Watkins, F. CNa. S. K. Estrogen stimulation differentially impacts human male and female antigen-specific T cell anti-tumor function and polyfunctionality. Gender Genome 1, 167-179. https://doi.org/10.1089/gg.2017.0014 (2017).

15. Lissauer, D. et al. Progesterone promotes maternal-fetal tolerance by reducing human maternal T-cell polyfunctionality and inducing a specific cytokine profile. Eur. J. Immunol. 45, 2858-2872. https://doi.org/10.1002/eji.201445404 (2015).

16. Yao, Y., Li, H., Ding, J., Xia, Y. \& Wang, L. Progesterone impairs antigen-non-specific immune protection by CD8 T memory cells via interferon-gamma gene hypermethylation. PLoS Pathog. 13, e1006736. https://doi.org/10.1371/journal.ppat.1006736 (2017).

17. Kiniry, B. E. et al. Predominance of weakly cytotoxic, T-betLowEomesNeg CD8+ T-cells in human gastrointestinal mucosa: Implications for HIV infection. Mucosal Immunol. 10, 1008-1020. https://doi.org/10.1038/mi.2016.100 (2017).

18. Wira, C. R. \& Rossoll, R. M. Oestradiol regulation of antigen presentation by uterine stromal cells: Role of transforming growth factor-beta production by epithelial cells in mediating antigen-presenting cell function. Immunology 109, 398-406 (2003).

19. Omwandho, C. O., Konrad, L., Halis, G., Oehmke, F. \& Tinneberg, H. R. Role of TGF-betas in normal human endometrium and endometriosis. Hum. Reprod. 25, 101-109. https://doi.org/10.1093/humrep/dep382 (2010).

20. McNatty, K. P. et al. Concentration of oestrogens and androgens in human ovarian venous plasma and follicular fluid throughout the menstrual cycle. J. Endocrinol. 71, 77-85 (1976).

21. Fahey, J. V., Schaefer, T. M. \& Wira, C. R. Sex hormone modulation of human uterine epithelial cell immune responses. Integr. Comp. Biol. 46, 1082-1087. https://doi.org/10.1093/icb/icl036 (2006).

22. Mor, G., Aldo, P. \& Alvero, A. B. The unique immunological and microbial aspects of pregnancy. Nat. Rev. Immunol. 17, 469-482. https://doi.org/10.1038/nri.2017.64 (2017).

23. Carr, B. R. \& Wilson, J. D. in Harrison's Principles of Internal Medicine Vol. 2 (eds E. Baunwald et al.) 1820-1821 (McGraw Hill, 1987).

24. Erlebacher, A. Mechanisms of T cell tolerance towards the allogeneic fetus. Nat. Rev. Immunol. 13, 23-33. https://doi.org/10.1038/ nri3361 (2013).

25. Dosiou, C. et al. Expression of membrane progesterone receptors on human T lymphocytes and Jurkat cells and activation of G-proteins by progesterone. J. Endocrinol. 196, 67-77. https://doi.org/10.1677/JOE-07-0317 (2008).

26. Hersperger, A. R., Makedonas, G. \& Betts, M. R. Flow cytometric detection of perforin upregulation in human CD8 T cells. Cytom Part A J Int Soc Anal Cytol 73, 1050-1057. https://doi.org/10.1002/cyto.a.20596 (2008).

27. Casslén, B., Sandberg, T., Gustavsson, B., Willén, R. \& Nilbert, M. Transforming growth factor betal in the human endometrium. Cyclic variation, increased expression by estradiol and progesterone, and regulation of plasminogen activators and plasminogen activator inhibitor-1. Biol. Reprod. 58, 1343-1350. https://doi.org/10.1095/biolreprod58.6.1343 (1998).

28. Ace, C. I. \& Okulicz, W. C. Differential gene regulation by estrogen and progesterone in the primate endometrium. Mol. Cell. Endocrinol. 115, 95-103. https://doi.org/10.1016/0303-7207(95)03674-v (1995).

29. Shen, Z. et al. Estradiol regulation of nucleotidases in female reproductive tract epithelial cells and fibroblasts. PLoS ONE 8, e69854. https://doi.org/10.1371/journal.pone.0069854 (2013).

30. Fahey, J. V. et al. Estradiol selectively regulates innate immune function by polarized human uterine epithelial cells in culture. Mucosal Immunol. 1, 317-325. https://doi.org/10.1038/mi.2008.20 (2008).

31. Barcellos-Hoff, M. H. \& Dix, T. A. Redox-mediated activation of latent transforming growth factor-beta 1. Mol. Endocrinol. 10, 1077-1083. https://doi.org/10.1210/mend.10.9.8885242 (1996).

32. Wipff, P. J. \& Hinz, B. Integrins and the activation of latent transforming growth factor beta1-An intimate relationship. Eur. J. Cell Biol. 87, 601-615. https://doi.org/10.1016/j.ejcb.2008.01.012 (2008).

33. Reed, B. G. \& Carr, B. R. in Endotext (eds K. R. Feingold et al.) (2000).

34. Chávez-Galán, L., Arenas-Del Angel, M. C., Zenteno, E., Chávez, R. \& Lascurain, R. Cell death mechanisms induced by cytotoxic lymphocytes. Cell. Mol. Immunol. 6, 15-25. https://doi.org/10.1038/cmi.2009.3 (2009).

35. Shanmugasundaram, U. et al. Phenotype and functionality of CD4+ and CD8+ T cells in the upper reproductive tract of healthy premenopausal women. Am. J. Reprod. Immunol. 71, 95-108. https://doi.org/10.1111/aji.12182 (2014).

36. King, A. E. \& Critchley, H. O. D. Oestrogen and progesterone regulation of inflammatory processes in the human endometrium. J. Steroid Biochem. Mol. Biol. 120, 116-126. https://doi.org/10.1016/j.jsbmb.2010.01.003 (2010).

37. Mselle, T. F. et al. Unique characteristics of NK cells throughout the human female reproductive tract. Clin. Immunol. 124, 69-76. https://doi.org/10.1016/j.clim.2007.04.008 (2007).

38. Bulmer, J. N., Morrison, L., Longfellow, M., Ritson, A. \& Pace, D. Granulated lymphocytes in human endometrium: Histochemical and immunohistochemical studies. Hum. Reprod. 6, 791-798. https://doi.org/10.1093/oxfordjournals.humrep.a137430 (1991). 
39. Zhang, J., Chen, Z., Smith, G. N. \& Croy, B. A. Natural killer cell-triggered vascular transformation: Maternal care before birth?. Cell. Mol. Immunol. 8, 1-11. https://doi.org/10.1038/cmi.2010.38 (2011).

40. Souza, S. S. et al. Influence of menstrual cycle on NK activity. J. Reprod. Immunol. 50, 151-159. https://doi.org/10.1016/s0165 -0378(00)00091-7 (2001).

41. Lee, S. et al. Fluctuation of peripheral blood T, B, and NK cells during a menstrual cycle of normal healthy women. J. Immunol. 185, 756-762. https://doi.org/10.4049/jimmunol.0904192 (2010).

42. Jones, R. K., Bulmer, J. N. \& Searle, R. F. Cytotoxic activity of endometrial granulated lymphocytes during the menstrual cycle in humans1. Biol. Reprod. 57, 1217-1222. https://doi.org/10.1095/biolreprod57.5.1217 (1997).

43. Rodriguez-Garcia, M., Fortier, J. M., Barr, F. D. \& Wira, C. R. Isolation of dendritic cells from the human female reproductive tract for phenotypical and functional studies. J. Vis. Exp. JoVE https://doi.org/10.3791/57100 (2018).

44. Rodriguez-Garcia, M. et al. Dendritic cells from the human female reproductive tract rapidly capture and respond to HIV. Mucosal Immunol. 10, 531-544. https://doi.org/10.1038/mi.2016.72 (2017).

45. Barr, F. D., Ochsenbauer, C., Wira, C. R. \& Rodriguez-Garcia, M. Neutrophil extracellular traps prevent HIV infection in the female genital tract. Mucosal Immunol. 11, 1420-1428. https://doi.org/10.1038/s41385-018-0045-0 (2018).

46. Fahey, J. V., Schaefer, T. M., Channon, J. Y. \& Wira, C. R. Secretion of cytokines and chemokines by polarized human epithelial cells from the female reproductive tract. Hum. Reprod. 20, 1439-1446. https://doi.org/10.1093/humrep/deh806 (2005).

47. Fahey, J. V. \& Wira, C. R. Effect of menstrual status on anti-bacterial activity and secretory leukocyte protease inhibitor production by human uterine epithelial cells in culture. J. Infect. Dis. 185, 1606-1613 (2002).

48. Meter, R. A., Wira, C. R. \& Fahey, J. V. Secretion of monocyte chemotactic protein-1 by human uterine epithelium directs monocyte migration in culture. Fertil. Steril. 84, 191-201. https://doi.org/10.1016/j.fertnstert.2005.01.104 (2005).

49. Ochiel, D. O. et al. Uterine epithelial cell regulation of DC-SIGN expression inhibits transmitted/founder HIV-1 trans infection by immature dendritic cells. PLOS ONE 5, e14306. https://doi.org/10.1371/journal.pone.0014306 (2010).

50. Rodriguez-Garcia, M. et al. Estradiol reduces susceptibility of CD4+ T cells and macrophages to HIV-infection. PLoS ONE 8, e62069. https://doi.org/10.1371/journal.pone.0062069 (2013).

\section{Acknowledgements}

This study supported by NIH Grants AI117739 (CW), AG064794 (CW), AG060801 (MR-G), and NCCC Prouty Pilot Grants (CW). Flow cytometric analysis was carried out in DartLab, the Shared Resource at Dartmouth supported by (P30CA023108-37) and (P30GM103415-15). We thank Fiona Barr, Richard Rossoll and Danial Hopkins for technical assistance. We also thank the study participants, Pathologists, Obstetrics, and Gynecology surgeons, operating room nurses, and support personnel at Dartmouth-Hitchcock Medical Center.

\section{Author contributions}

Z.S., C.W. and M.R.-G. designed the research and wrote the manuscript. M.R.-G., Z.S., and M.P. conducted experiments and acquired data and analyzed data. All authors approved the manuscript.

\section{Competing interests}

The authors declare no competing interests.

\section{Additional information}

Correspondence and requests for materials should be addressed to C.R.W.

Reprints and permissions information is available at www.nature.com/reprints.

Publisher's note Springer Nature remains neutral with regard to jurisdictional claims in published maps and institutional affiliations.

(c) (i) Open Access This article is licensed under a Creative Commons Attribution 4.0 International c. License, which permits use, sharing, adaptation, distribution and reproduction in any medium or format, as long as you give appropriate credit to the original author(s) and the source, provide a link to the Creative Commons licence, and indicate if changes were made. The images or other third party material in this article are included in the article's Creative Commons licence, unless indicated otherwise in a credit line to the material. If material is not included in the article's Creative Commons licence and your intended use is not permitted by statutory regulation or exceeds the permitted use, you will need to obtain permission directly from the copyright holder. To view a copy of this licence, visit http://creativecommons.org/licenses/by/4.0/.

(c) The Author(s) 2021 